\title{
Co-relation of endometrial thickness by transvaginal sonogram with histopathology pattern in abnormal uterine bleeding: a study from South India
}

\author{
Chippy Tess Mathew ${ }^{1 *}$, Uma Maheswari², Karthikeyan Shanmugam ${ }^{3}$
}

\begin{abstract}
${ }^{1}$ Department of Obstetrics and Gynecology, ${ }^{2}$ Department of Pathology, ${ }^{3}$ Department of Community Medicine, PSG Institute of Medical Sciences and Research, Coimbatore (Affiliated to Tamil Nadu Dr. MGR Medical University), Tamil Nadu, India
\end{abstract}

Received: 04 February 2020

Accepted: 29 February 2020

*Correspondence:

Dr. Chippy Tess Mathew,

E-mail: chippybivin@gmail.com

Copyright: (C) the author(s), publisher and licensee Medip Academy. This is an open-access article distributed under the terms of the Creative Commons Attribution Non-Commercial License, which permits unrestricted non-commercial use, distribution, and reproduction in any medium, provided the original work is properly cited.

\begin{abstract}
Background: Under normal circumstances, a woman's uterus sheds a limited amount of blood during each menstrual period (around $80 \mathrm{ml}$ ). Bleeding that occurs erratically or excessive menstrual bleeding is called abnormal uterine bleeding (AUB). The causes of AUB are many and varied. Initial investigations include transvaginal ultrasound and histopathologic assessment of the endometrium. Objective of this study was to evaluation of endometrial thickness with trans-vaginal ultrasound and its correlation with histopathology by dilatation and curettage in abnormal uterine bleeding. To determine the efficacy of transvaginal ultrasound in evaluating the endometrial thickness. To correlate the endometrial thickness by transvaginal ultrasound with endometrial histopathology in women with AUB.

Methods: It is a retrospective observational study. All reproductive and perimenopausal age group women who underwent dilatation and curettage for abnormal uterine bleeding during the period June 2014-June 2016 was taken and analyzed and correlated with their endometrial thickness measured with Transvaginal ultrasound.

Results: Around 478 patients who underwent endometrial sampling over a period of two years were analyzed. Maximum number of patients were in the fourth decade and the overweight category 36.6\%. Proliferative endometrium was the most common histopathologic picture (44.76\%). Detection of precancerous lesions were-5.87\% and endometrial cancer was $1.05 \%$.

Conclusions: An ET of $8 \mathrm{~mm}$ and above gave 100\% sensitivity and negative predictive value for precancerous and cancerous lesions.
\end{abstract}

Keywords: Abnormal uterine bleeding, Dilatation and curettage, Endometrial hyperplasia and cancer, Endometrial thickness, Transvaginal ultrasound

\section{NTRODUCTION}

Abnormal uterine bleeding is one of the most common gynecological problems in patients approaching the outpatient clinics in the country. These complaints definitely affect the quality of life of the patient. The etiology of AUB varies with the age group of the patient. There is the PALM COEIN classification for AUB by FIGO. ${ }^{1}$ There are many diagnostic modalities for evaluating endometrial pathologies in women who have AUB. Transvaginal sonogram (TVS) has permitted the use of higher frequency ultrasound waves at greater proximity of the uterus. It is a relatively cheap and noninvasive diagnostic modality for studying the endometrial pattern and its thickness and at the same time to exclude organic pathology in case of AUB while dilatation and curettage gives us a definitive histopathologic picture. This study attempts to correlate the USG findings and histopathology in patients with AUB. The gold standard 
for diagnosing AUB is hysteroscopy and directed biopsy but it is expensive when compared to the simple endometrial sampling.

According to the PALM COIEN classification the causes of AUB can be divided into structural and non-structural cause which is given in detail in Table 1.

Table 1: PALM COEIN classification for AUB. ${ }^{1}$

\begin{tabular}{|ll|}
\hline Structural & Non structural \\
\hline Polyps & Coagulopathy \\
\hline Adenomyosis & Ovulatory dysfunction \\
\hline Leiomyomas & Endometrial hyperplasia \\
\hline Malignancy & Iatrogenic \\
\hline & Not yet specified \\
\hline
\end{tabular}

\section{Aims and objectives of this study were}

- Evaluation of endometrial thickness with transvaginal ultrasound and its correlation with histopathology by dilatation and curettage in abnormal uterine bleeding.

- To determine the efficacy of Transvaginal ultrasound in evaluating the endometrial thickness.

- To correlate the endometrial thickness by Transvaginal ultrasound with endometrial histopathology in women with AUB.

\section{METHODS}

Retrospective observational study included all reproductive and perimenopausal age group women who underwent dilatation and curettage for abnormal uterine bleeding during the period June 2014 to June 2016.

\section{Inclusion criteria}

- AUB in all reproductive and perimenopausal women

- Only gynecological indications for dilatation and curettage.

\section{Exclusion criteria}

- Unmarried women

- Pregnancy and related causes of bleeding

- Postmenopausal bleeding

- Puberty menorrhagia.

From minor and major OT registers, list of all D and Cs which were done during 2014 June to 2016 June was taken. Cases which satisfied the inclusion and exclusion criteria was taken and analyzed

\section{Statistical analysis}

Chi square test was used for the statistical analysis.

\section{RESULTS}

All the patients with abnormal uterine bleeding, fitting the inclusion criteria, who underwent endometrial sampling was taken for analysis. There were around 478 patients. All of them had a premenstrual ultrasound before the procedure. The age distribution, parity, BMI, presenting complaints, the histopathology and the endometrial thickness by TVS was evaluated. The results are given below:

Of the 478 patients, the youngest patient was 22 years old and the oldest was 55 years, the mean age was 38.5 years. Maximum number of patients were in the 41-50 years age group which was $60.25 \%$ and the least in the $20-30$ years group and was $4.6 \%$ (Table 2 ).

Table 2: Age distribution of patients with AUB.

\begin{tabular}{|ll|l|}
\hline Age & No. of cases & $\%$ \\
\hline $20-30$ & 22 & $4.60 \%$ \\
\hline $31-40$ & 117 & $24.48 \%$ \\
\hline $41-50$ & 288 & $60.25 \%$ \\
\hline $51-60$ & 51 & $10.67 \%$ \\
\hline Total & 478 & $100 \%$ \\
\hline
\end{tabular}

Majority of the patients were multiparious i.e. $79.71 \%$ and $2.93 \%$ was nulliparous as seen in (Table 3 ).

Table 3: Parity of the patients with AUB.

\begin{tabular}{|c|c|c|}
\hline Parity & No. of cases & $\%$ \\
\hline Nullipara & 14 & $2.93 \%$ \\
\hline Primipara & 83 & $17.36 \%$ \\
\hline Multipara & 381 & $79.71 \%$ \\
\hline Total & 478 & $100 \%$ \\
\hline
\end{tabular}

A total $35.8 \%$ of the patients under analysis were of the normal BMI and maximum numbers of patients were overweight $-36.6 \%$ and the least number of patients were underweighted i.e. $3.3 \%$ as given in Table 4 .

Table 4: BMI of patients with AUB.

\begin{tabular}{|lll|}
\hline BMI & No. of cases & $\%$ \\
\hline Underweight & 16 & $3.3 \%$ \\
\hline Normal & 171 & $35.8 \%$ \\
\hline Overweight & 175 & $36.6 \%$ \\
\hline Obese & 116 & $24.3 \%$ \\
\hline Total & 478 & $100 \%$ \\
\hline
\end{tabular}

A total $98.3 \%$ had heavy menstrual bleeding among the 478 patients and $72.4 \%$ had undergone tubal ligation. Among the other USG findings, adenomyotic changes were found in $11.1 \%$, fibroids seen in $18.6 \%$, while simple ovarian cysts were found in $11.7 \%$ and $\mathrm{PCO}$ in $4.2 \%$. 
There were 42 cases of hormone induced changes, 25 menstrul endometium, 17 were inadequate and 2 were TB endometritis which were all entered under others.44.7\% were having proliferative phases (Figure 1), of which $29.7 \%$ was disordered proliferative (Figure 2). 30.33\% showed secretory changes (Figure 3) endometrial adenocarcinoma (Figure 4) was found in $1.05 \%$ of the cases and hyperplasia was seen in $5.86 \%$ (Table 5 ).

Table 5: Histopathology findings in study population.

\begin{tabular}{|c|c|c|c|}
\hline HPR & $\begin{array}{l}\text { No. of } \\
\text { cases }\end{array}$ & Percenta & \\
\hline Disordered proliferative & 142 & $29.7 \%$ & \multirow{2}{*}{$44.76 \%$} \\
\hline Proliferative & 72 & $15.06 \%$ & \\
\hline Secretory & 145 & $30.33 \%$ & \\
\hline Endometrial hyperplasia & 28 & $5.86 \%$ & \\
\hline Endometrial carcinoma & 5 & $1.05 \%$ & \\
\hline Others & 86 & $17.99 \%$ & \\
\hline Total & 478 & $100 \%$ & \\
\hline
\end{tabular}

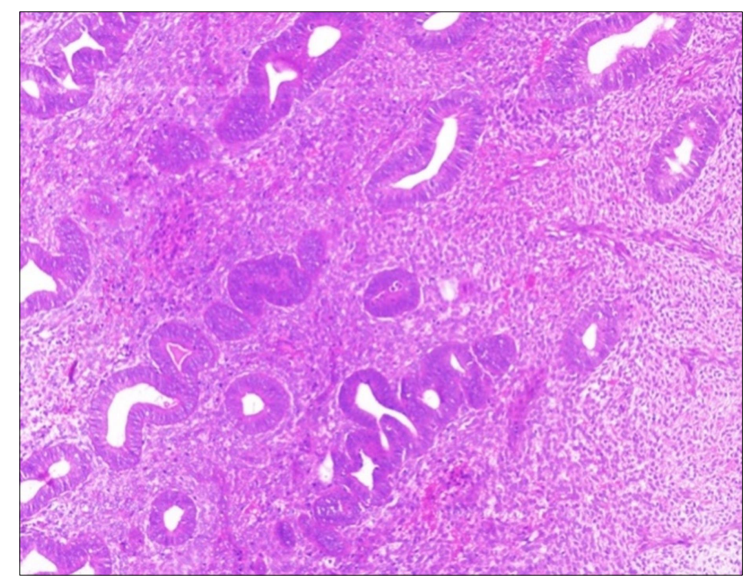

Figure 1: Proliferative endometrium.

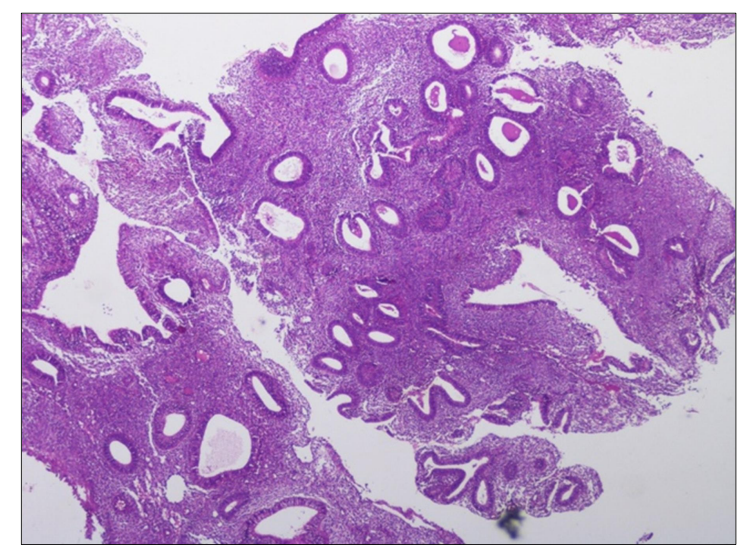

Figure 2: Disordered proliferative.

Among the hyperplasia, 50\% was simple hyperplasia without atypia. Atypical hyperplasia (Figure 5) was found in 12 cases. Complex hyperplasia was found in 13 out of the 28 cases of hyperplasia of which complex atypical was 11 cases (Table 6).

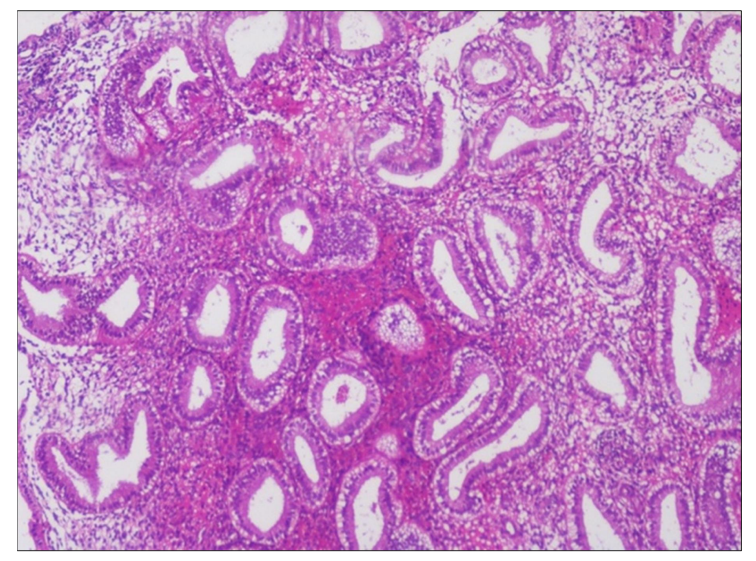

Figure 3: Secretory endometrium.

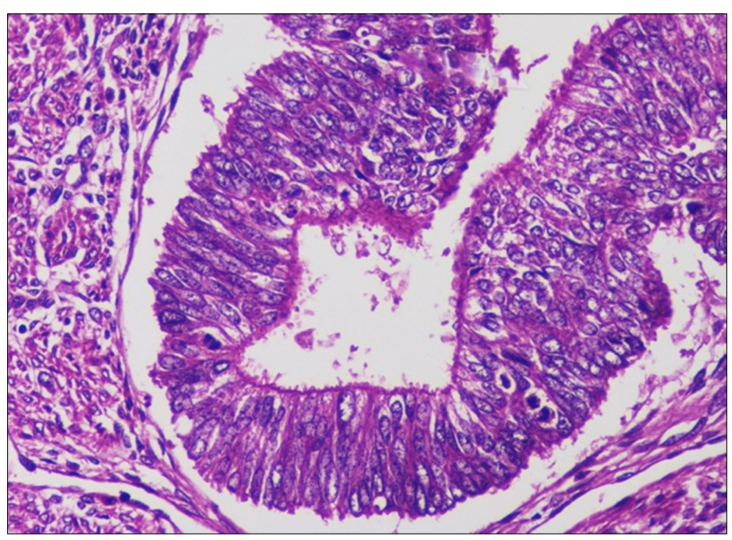

Figure 4: Adenocarcinoma.

Table 6: Cases of endometrial hyperplasia.

\begin{tabular}{|lll|}
\hline Type of hyperplasia & Number & $\%$ \\
\hline Simple hyperplasia without atypia & 14 & $50 \%$ \\
\hline Simple hyperplasia with atypia & 1 & $3.57 \%$ \\
\hline Complex hyperplasia without atypia & 2 & $7.14 \%$ \\
\hline Complex hyperplasia with atypia & 11 & $39.29 \%$ \\
\hline Total & 28 & $100 \%$ \\
\hline
\end{tabular}

Endometrial thickness was $8 \mathrm{~mm}$ and above up to $15 \mathrm{~mm}$ in majority of cases of AUB-54.81\%. ET less than $8 \mathrm{~mm}$ was found only in $19.3 \%$ of the study population.ET 15 $\mathrm{mm}$ and above was also less which was $25.5 \%$ (Table 7 ). ET less than $4 \mathrm{~mm}$ in AUB was very less-only $1.67 \%$. One ET was not measured due to diffuse adenomyosis. Out of the 477 patients whose endometrial thickness were measured, all the five cases of endometrial carcinoma was found with an ET $\geq 15 \mathrm{~mm}$ among the 28 cases of endometrial hyperplasia 12 cases of hyperplasia were also found with ET $\geq 15 \mathrm{~mm}$ and the rest 16 cases had ET $\geq 8$-15 (Table 8). Surprisingly all the five cases of carcinoma was endometrioid adenocarcinoma. 
It was found in this study that proliferative and secretory endometrium was maximum when the endometrial thickness was $\geq 8-15 \mathrm{~mm}$ and least with an ET less than 4 mm (Table 9).

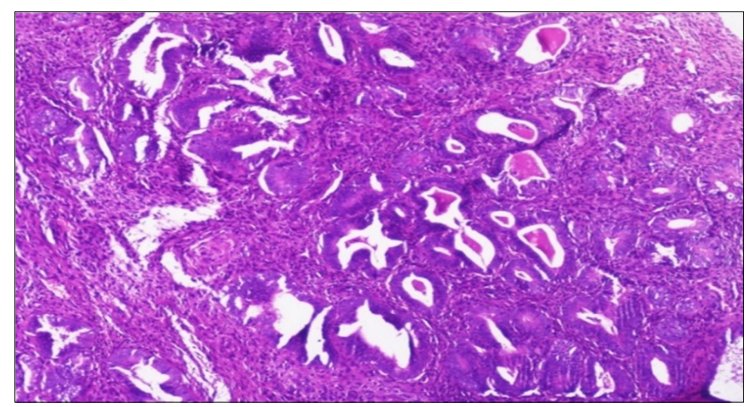

Figure 5: Atypical hyperplasia.
Table 7: Endometrial thicknesses by transvaginal ultrasound.

\begin{tabular}{|lll|}
\hline ET IN mm & Number & $\%$ \\
\hline$<4$ & 8 & $1.67 \%$ \\
\hline $4-8$ & 85 & $17.78 \%$ \\
\hline$\geq 8-15$ & 262 & $54.81 \%$ \\
\hline$\geq 15$ & 122 & $25.52 \%$ \\
\hline Not measured & 1 & $0.22 \%$ \\
\hline Total & 478 & $100 \%$ \\
\hline
\end{tabular}

If we take $8 \mathrm{~mm}$ as the cut off, we can see that in this study population all the cases of hyperplasia and malignancy had an ET $\geq 8 \mathrm{~mm}$. Out of the 384 cases with ET $\geq 8 \mathrm{~mm} 28$ cases had hyperplasia and five patients had endometrial carcinoma i.e. $8.59 \%$ (Table 10).

Table 8: Co-relation of et with endometrial hyperplasia and carcinoma.

\begin{tabular}{|llllll|}
\hline ET in $\mathbf{m m}$ & Number & Endometrial hyperplasia & $\%$ & Endometrioid carcinoma & $\%$ \\
\hline$\geq 15$ & 122 & 12 & $9.84 \%$ & 5 & $4.46 \%$ \\
\hline$\geq 8-15$ & 262 & 16 & $6.11 \%$ & 0 & $0 \%$ \\
\hline $4-8$ & 85 & 0 & $0 \%$ & 0 & $0 \%$ \\
\hline$<4$ & 8 & 0 & $0 \%$ & 0 & $0 \%$ \\
\hline Total & 477 & 28 & $5.87 \%$ & 5 & $4.46 \%$ \\
\hline
\end{tabular}

Table 9: Co-relation of et by TVS and histopathology.

\begin{tabular}{|lllllll|}
\hline ET & Number & Proliferative & Secretory & EH & Carcinoma & Others \\
\hline$<4 \mathrm{~mm}$ & 8 & 3 & 3 & 0 & 0 & 2 \\
\hline $4-<8$ & 85 & 34 & 29 & 0 & 0 & 22 \\
\hline$\geq 8-15$ & 262 & 121 & 86 & 16 & 0 & 39 \\
\hline$\geq 15$ & 122 & 56 & 27 & 12 & 5 & 22 \\
\hline Total & 477 & 214 & 145 & 28 & 5 & 85 \\
\hline
\end{tabular}

Table 10: Co-relation of endometrial thickness with hyperplasia and malignancy.

\begin{tabular}{|l|lll|}
\hline $\begin{array}{l}\text { ET in } \\
\text { mm }\end{array}$ & Number & $\begin{array}{l}\text { Hyperplasia and } \\
\text { carcinoma }\end{array}$ & $\%$ \\
\hline$\geq 8$ & 384 & 33 & $8.59 \%$ \\
\hline$<8$ & 94 & 0 & $0 \%$ \\
\hline
\end{tabular}

Table 11: Co-relation of endometrial thickness with HPR.

\begin{tabular}{|l|l|l|l|}
\hline $\begin{array}{l}\text { ET in } \\
\text { mm }\end{array}$ & Number & $\begin{array}{l}\text { Hyperplasia } \\
\text { and carcinoma }\end{array}$ & $\begin{array}{l}\text { Not having } \\
\text { carcinoma }\end{array}$ \\
\hline$\geq 8$ & 384 & 33 (a) & $351(\mathrm{~b})$ \\
\hline$<8$ & 94 & 0 (c) & $94(\mathrm{~d})$ \\
\hline
\end{tabular}

Sensitivity, specificity, the positive and negative predictive value for an ET of $\geq 8 \mathrm{~mm}$ was calculated. 94 patients with ET less than 8 and 351 patients with ET $\geq 8$ $\mathrm{mm}$ did not have carcinoma (Table 11).
- $\quad$ Sensitivity $=a / a+c=33 / 33=100 \%$

- $\quad$ Specificity $=d / b+d=94 / 445=21.12 \%$

- $\quad$ Positive predictive value $=\mathrm{a} / \mathrm{a}+\mathrm{b}=33 / 384=8.59 \%$

- $\quad$ Negative predictive value $=\mathrm{d} / \mathrm{c}+\mathrm{d}=94 / 94=100 \%$

\section{DISCUSSION}

Abnormal uterine bleeding is a very common diagnosis in the op population. According to this study the maximum age groups of the patients were in the perimenopausal age of $41-50$ years-around $60.25 \%$. This is similar to the study by Shobitha et al $-68.1 \%$ in the same age group while it was $38 \%$ in a study by Mahapatra $\mathrm{M}$ et al where the study group was less. ${ }^{2,3}$

The youngest patient was a 22-year-old primary infertility patient with heavy menstrual bleeding for which diagnostic curettage was done and had an ET of 6 $\mathrm{mm}$ and secretory endometrium. 
In this study, $79.7 \%$ were multiparious while $2.93 \%$ were nulli, in almost all the studies this is similar. This is in accordance to the study by Nidhi et al, where $88 \%$ were multipara and $1.2 \%$ were nulliparous. ${ }^{4}$ In a study by Betha $\mathrm{K}$ et al $81 \%$ were multipara. ${ }^{5}$

BMI was in the overweight category in $36.6 \%$ and obese in $24.3 \%$ in this study which is similar to the study in Iran by Kazamijalezah et al, where it was $33 \%$ and also with the study by Sahai A et al, where $56.2 \%$ were in overweight category and obese was $25 \%{ }^{6,7}$

There was heavy menstrual bleeding in $98 \%$ of patients.

Of these 478 patients only 39 had diabetes as risk factor and out of 39 one had endometrial carcinoma.

When we analyze the histopathologic findings of the 478 cases $44.5 \%$ was proliferative endometrium, of this disordered proliferative endometrium seems to be the commonest, in a study by Elavarasan et al, where disordered proliferative endometrium seems to be the commonest pattern observed i.e. $31.1 \%{ }^{8}$ The term disordered proliferative endometrium refers to proliferative phase that does not seems to be appropriate for any one time in the menstrual cycle and mimics simple hyperplasia, but the process is focal rather than diffuse. Histologically there shows mild disorganization of architecture, with focal dilated glands, with normal gland to stromal ratio. In this study $30 \%$ was secretory endometrium; endometrial hyperplasia was found in $5.8 \%$ and endometrial cancer in $1 \%$.

Transvaginal ultrasound was done to assess the endometrial thickness and it was done in the premenstrual phase, of the 478 cases $54.8 \%$ had an ET of $\geq 8-15,25.5 \%$ had ET more than $15 \mathrm{~mm}$. In a study by Jikki et al, $57 \%$ had et $\geq 8 \mathrm{~mm}$ which is similar to this study of $54 \%$. ${ }^{9}$

In the study by Jikki et al, the endometrial hyperplasia was seen in $96.4 \%$ cases when ET was more than $8 \mathrm{~mm}$ and in this study $100 \%$ of the patients with endometrial hyperplasia had ET $\geq 8 \mathrm{~mm} .{ }^{9}$ In this study $100 \%$ cases of endometrial carcinoma occurred with ET $\geq 15$ and all cases of hyperplasia had ET $\geq 8 \mathrm{~mm}$.

Simple hyperplasia without atypia was $50 \%$ in this study which was comparable to $62 \%$ in a study by Tabata et al. $^{10}$

Complex endometrial hyperplasia was $14.8 \%$ in a study conducted by Idris et al, while their atypical hyperplasia was only $2 \%$ whereas atypical hyperplasia was $42.4 \%$ in this study. ${ }^{11}$ This may be because of the fact that most of the patients in the study group were in the fourth decade $(60 \%)$ and in their study was in the third decade (80\%).

Of the 384 cases with ET $\geq 8 \mathrm{~mm}, 33$ had endometrial hyperplasia and carcinoma, and 351 did not have e/o hyperplasia and carcinoma, none of the cases below $8 \mathrm{~mm}$ had any e/o hyperplasia or carcinoma. Sensitivity and negative predictive value was $100 \%$ for an ET of $\geq 8 \mathrm{~mm}$. This is similar to studies by Chatpavit Getpook an ET of $8 \mathrm{~mm}$ showed optimal sensitivity and specificity $-83.9 \%$ and $58.8 \%$ respectively and $90.4 \%$ negative predictive value for an abnormal endometrium. ${ }^{12}$ They concluded that an ET of $8 \mathrm{~mm}$ or less is less likely to be associated with malignant pathologies. In this study the negative predictive value was $100 \%$ and sensitivity was $100 \%$ but the specificity was only $21.1 \%$. According to a study by Ozdemir $\mathrm{S}$ et al, there was negative predictive value of $95.6 \%$, sensitivity and specificity of 83.6 and $56.4 \%$ respectively for an ET of $8 \mathrm{~mm} .^{13}$

Kurman et al, classified hyperplasia in to simple and complex and subcategory as atypical. ${ }^{14}$ The 2014 revised WHO classification simply separates endometrial hyperplasia into 2 groups-hyperplasia without atypia and atypical hyperplasia. ${ }^{15}$ According to the EIN classification all atypical endometrial hyperplasia is classified as endometrial intraepithelial neoplasia. ${ }^{15}$ Progesterone was found to cause regression in $90 \%$ cases with hyperplasia.

The RCOG cutoff of ET is less than $7 \mathrm{~mm}$ below which there is no endometrial hyperplasia in a prospective study of 56 women with pcos. ${ }^{11,16}$ In studies by Gianella et al, $11 \mathrm{~mm}$ was taken as the cut off.

The most common presenting symptoms of endometrial hyperplasia is abnormal uterine bleeding. According to studies, the risk of progression of simple hyperplasia to carcinoma is $1 \%$ and complex hyperplasia with atypia is $29 \%{ }^{18}$

\section{CONCLUSION}

The clinical importance of endometrial hyperplasia is because of its progression to endometrial carcinoma. An ET of $8 \mathrm{~mm}$ in this study gives a $100 \%$ negative predictive value for hyperplasia and carcinoma and can be taken as a cut off for deciding the patients for dilatation and curettage especially in low risk patients.

\section{Funding: No funding sources} Conflict of interest: None declared

Ethical approval: The study was approved by the Institutional Ethics Committee of PSGIMSR

\section{REFERENCES}

1. Munro MG, Critchley HO, Broder MS, Fraser IS. FIGO classification system (PALM COIEN) for causes of abnormal uterine bleeding in non-gravid women of reproductive age. FIGO Working Group on Menstrual Disorders. Int J Gynaecol Obstet. 2011;113:3-13.

2. Shobhitha GL, Kumari VI, Priya PL, Sundari BT. Endometrial study by TVS and It's correlation with 
histopathology in abnormal uterine bleeding. J Dental Med Sci. 2015;14(4):21-32.

3. Mahapatra M, Mishra P. Clinicopathological evaluation of abnormal uterine bleeding. J Health Res Rev. 2015;2:45-9

4. Meena N, Meena S. Correlation between histology and bleeding pattern in a case of AUB and risk factors analysis of AUB in reproductive age group. JMSCR. 2017;5(7):24629-34.

5. Betha K, Malvatu L, Talasani S Distribution of causes of abnormal uterine bleeding using new FIGO classification system-PALM COEIN: a rural tertiarybased study. Int J Reprod Contracept Obstet Gynecol. 2017;6(8):3523-7.

6. Kazemijaliseh H, Ramezani Tehrani F, BehboudiGandevani S, Khalili D, Hosseinpanah F, Azizi F. A Population-based study of the prevalence of abnormal uterine bleeding and its related factors among Iranian reproductive-age women: An updated data. Arch Iran Med. 2017;20(9):558-63.

7. Sharma AS, Gupta S. Analysis of body mass index in patients with abnormal uterine bleeding. Inter J Clin Obstet Gynaecol. 2019;3(1):92-5

8. Puvitha RD, Elavarasan T, Shruthi MS, Shylaja S. Histopathological study of endometrium in abnormal uterine bleeding an experience in a tertiary care centre of rural south India. Nat J Basic Med Sci. 2017;8:1.

9. Kalaiselvi PSJ. Thenmozhi G. A study on endometrial thickness by endovaginal sonography with histopathology in perimenopausal women in a tertiary care centre. Indian J Res. 2017;6(10):33-6.

10. Tabata T, Yamawaki T, Yabana T, Ida M, Nishimura K, Nose Y. Natural history of endometrial hyperplasia Arch Gynecol Obstet. 2001;265(2):85-8.

11. Takai IU, Bukar M, Mayun AA, Ugwa EA, Audu BM. Aisha abdurrahman endometrial hyperplasia: a 2 decade retrospective analysis of histopathological pattern at a university teaching hospital in Northern Nigeria Sub-Saharan. Afr J Med. 2016;3:171-5.

12. Getpook C, Wattanakumtornkul S. Endometrial thickness screening in premenopausal women with abnormal uterine bleeding. J Obstet Gynaecol Res. 2006;32(6):588-92 .

13. Özdemir S, Çelik Ç, Gezginç K, Kıreşi D, Esen H. Evaluation of endometrial thickness with transvaginal ultrasonography and histopathology in premenopausal women with abnormal vaginal bleeding. Arch Gynecol Obstet. 2010;282(4):395-9.

14. Kurman RJ, Kaminski PF, Norris HJ. The behavior of endometrial hyperplasia: a long-term study of "untreated" hyperplasia in 170 patients. Cancer. 1985;56:403-12.

15. Palmer JE, Perunovic B, Tidy JA. Endometrial hyperplasia. The Obstet Gynaecol. 2008;10(4):211-6.

16. Cheung AP. Ultrasound and menstrual history in predicting endometrial hyperplasia in polycystic ovary syndrome. Obstet Gynecol. 2001;98:325-31.

17. Giannella L, Cerami LB, Setti T, Bergamini E, Boselli F. Prediction of endometrial hyperplasia and cancer among premenopausal women with abnormal uterine bleeding. BioMed Res Inter. 2019;2019.

18. No GT. Management of Endometrial Hyperplasia. 2016. Available at: ttps://www.rcog.org.uk/globalassets/documents/guid elines/green-top-guidelines/gtg_67_endometrial hyperplasia.pdf. Accessed on $01^{\text {st }}$ February 2020.

Cite this article as: Mathew $\mathrm{CT}$, Maheswari $\mathrm{U}$, Shanmugam K. Co-relation of endometrial thickness by transvaginal sonogram with histopathology pattern in abnormal uterine bleeding: a study from south India. Int J Reprod Contracept Obstet Gynecol 2020;9:1416-21. 